Journal of Human Resource and Leadership

ISSN 2519-9099 (online)

Vol.5, Issue 1, No.4. pp 54 - 62, 2020

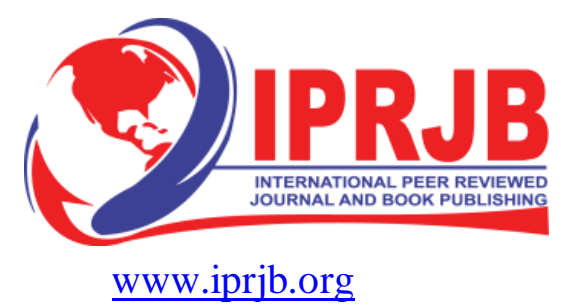

\title{
HOW TO IMPROVE SEARCH COMMITTEE EFFECTIVENESS: REDUCING THE DEGREE OF SUBJECTIVITY IN SEARCHING FOR AND SELECTING EDUCATIONAL LEADERS
}

\author{
${ }^{1 *}$ Ross Clayton, $\mathrm{PhD}$ \\ Dean Emeritus: Solomon Price School at the University of Southern California \\ Corresponding Author's E-mail: rossclayton34@gmail.com \\ ${ }^{2}$ Carolyn Borden, MPA \\ Corresponding Author's E-mail: carolynbordenconsulting@gmail.com
}

\begin{abstract}
Purpose: The purpose in this study was to propose and illustrate methods for structuring Search Committee processes so that committee members have a shared understanding of the leadership attributes desired of candidates and of the important contextual factors to be considered in assessing the suitability of the various candidates for the position.

Methodology: The study has substantial personal experiences with Search Committees and their decision processes; the article does not reflect an intent to do original research based on exploratory, experimental, or quasi-experimental research designs. No data collection is attempted; the reader will not find data driven analyses, or the results of hypotheses testing. Rather, the study intent was to provide readers with a logical set of ideas and tools that will aid them in conducting their leadership searches in a systematic rather than ad hoc manner. To identify and weight desired leadership attributes we have chosen to rely upon the writings of an illustrious group of individuals who have significant experience in leading public, private, and not for profit organizations, including higher education institutions. The study believes their books reflect "armchair empiricism" and provide distillations of their rich concrete leadership experiences. To identify and weight contextual factors to be taken into account in considering candidates for the specific organizational position to be filled, the study rely upon the seminal and classic empirical research study conducted by faculty of Harvard University.
\end{abstract}

Findings: That study of the high turnover among School Superintendents in New England is a benchmark in the development of Role Theory. The language for Role Analysis produced by that study is drawn upon in the study to illustrate how the contextual expectations of the candidates for the leadership position in question can be thoughtfully addressed.

Unique contribution to theory, practice and policy: The study has recommended the use of several theoretical/conceptual frameworks to structure Search Committee processes and improve their effectiveness in selecting the best qualified applicants for leadership roles. The study also describes a decision analysis method which, if employed, will lower the degree of subjectivity in Search Committee decision making processes.

Key Words: Leadership, Attributes, Search Committees, Assessment, Selection 
Journal of Human Resource and Leadership

ISSN 2519-9099 (online)

Vol.5, Issue 1, No.4. pp 54 - 62, 2020

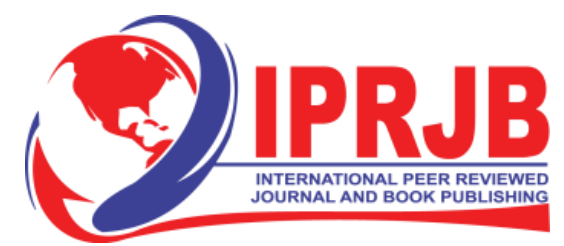

WWW.iprjb.org

\subsection{INTRODUCTION}

Each year, tens of thousands of Search Committees form to seek out and select leaders for positions in universities, colleges, school districts, and education related non-profit organizations. Consulting firms facilitate some of these searches, but many are carried out by committees of organizational employees appointed by boards or upper level executives. Irrespective of how these committees form, they consume many person hours of effort to culminate in hiring decision recommendations that directly reflect the values and subjective judgments of committee members.

A typical search committee process begins with the selection of a chair and committee members, and the advertisement of the position, duties, perhaps the pay range for the position and a deadline for applications. Once the deadline has passed, the chair distributes the applications to committee members to read and assess, and then committee meetings commence. Members share their assessments of the applicants and make decisions about who to invite for interviews. After the interviews, the committee evaluates the interviewees and recommends to the appointing authority who should receive an offer for the position. These application assessments, interviewee selections, and rankings are often accomplished using the BOGGSATT method - "a bunch of gals and guys sitting around a table talking."

Ultimately, subjective judgment in selecting a candidate is inescapable, but there are ways to lower the degree of subjectivity. In this article, we suggest an approach to structure search committee processes noted in Figure 1 below.

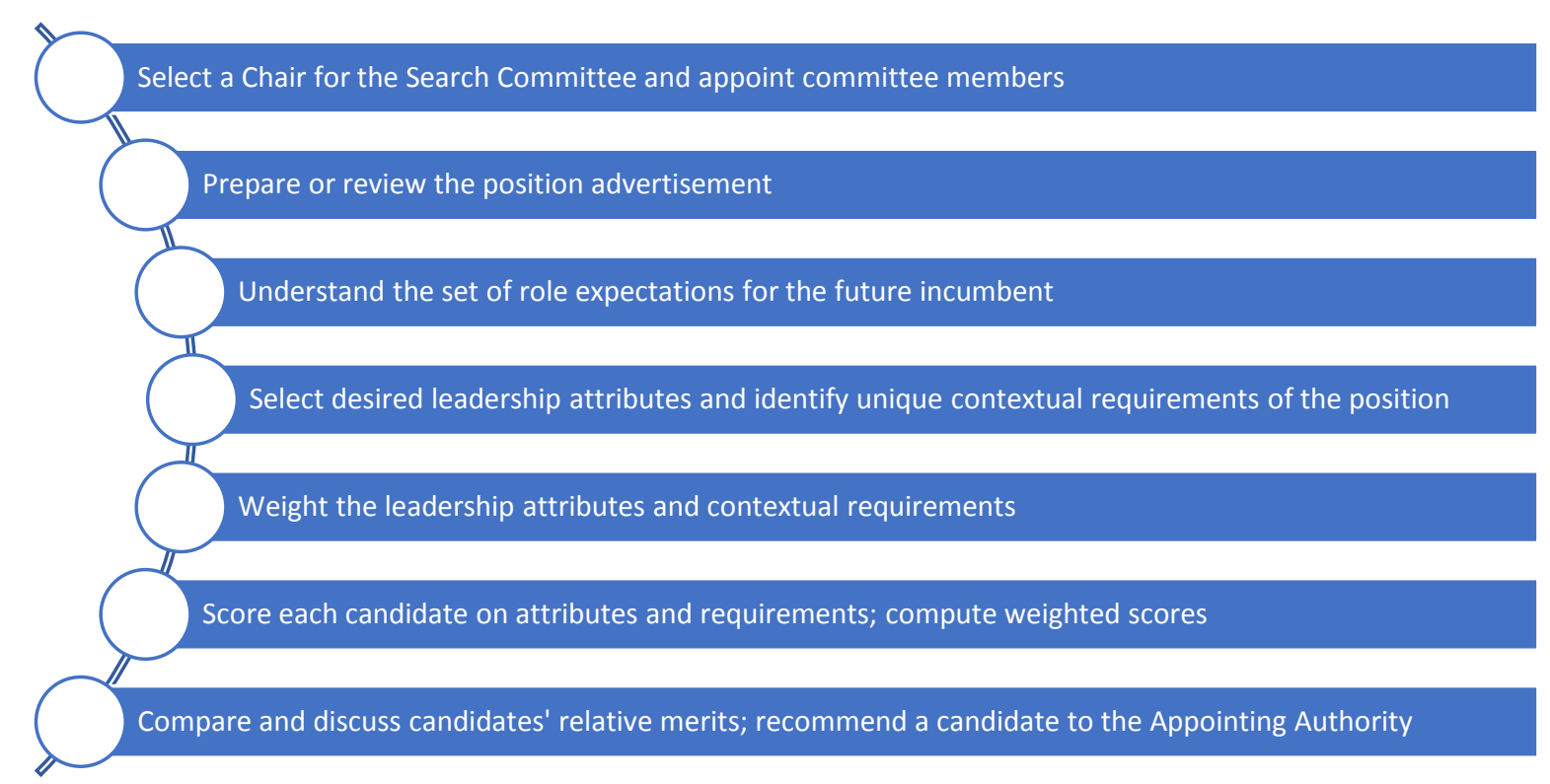

Figure 1: Sequential Flow of the Search Process

Our discussion focuses on three of the search processes steps: 
Journal of Human Resource and Leadership

ISSN 2519-9099 (online)

Vol.5, Issue 1, No.4. pp 54 - 62, 2020

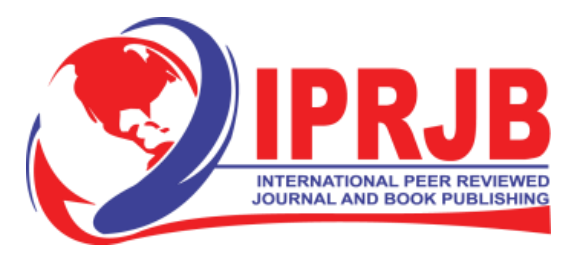

WWW.iprjb.org

1) select the leadership attributes that the participants wish to use to assess candidates;

2) identify the unique contextual requirements including diversity concerns for the specific position for which the search is being conducted; and

3) describe a method for systematically pooling the subjective judgments of committee members.

The method we advance for this latter step is multi-attribute utility analysis. This social science tool provides a means for committees to systematically pool their subjective judgments. This article discusses and illustrates how a simplified version of this social science tool can be used to lend structure to committee decision processes.

\subsection{ATTRIBUTES OF EFFECTIVE LEADERS}

There is a vast literature on this topic. A colleague, the late Warren Bennis, was one of the main contributors to that literature. His book, Essentials of Leadership, provides a valuable introduction to leadership literature. For the purposes of this paper, four authors are chosen who have written about their experience-based insights into the attributes of effective leaders. These authors are John Gardner, Admiral James Stavridis, USN (RET.), Robert M. Gates, and Steven B. Sample.

John Gardner was President of the Carnegie Corporation and the Carnegie Foundation. He served as Secretary of the Department of Health, Education and Welfare, and was Founding Chairman of Common Cause and a Co-Founder of the Independent Sector. His book, On Leadership, is a classic still in use in the fields of Business Administration and Public Management. Admiral Stavridis had a distinguished career in the Navy, served as Supreme Allied Commander of NATO, and is now an Analyst for NBC, and a columnist for Time and Bloomberg Opinion. His book, Sailing True North, examines the leadership qualities of Admirals. Robert Gates served as Secretary of Defense for two Presidents, Director of the CIA, President of Texas A\&M University, and Chancellor of the College of William \& Mary. His book, A Passion For Leadership, provides insights into leadership he acquired over his career. Steven Sample served as President of SUNY Albany and then the University of Southern California. His book, The Contrarian's Guide To Leadership, contains experienced based wisdom into university leadership. Each of the four authors noted above has shared his experience-based insights into the attributes of effective leadership. This article pools their insights and assembles a list of ten Leadership attributes that committees can use in their search and selection processes as shown in Table 1 below. 
Journal of Human Resource and Leadership

ISSN 2519-9099 (online)

Vol.5, Issue 1, No.4. pp 54 - 62, 2020

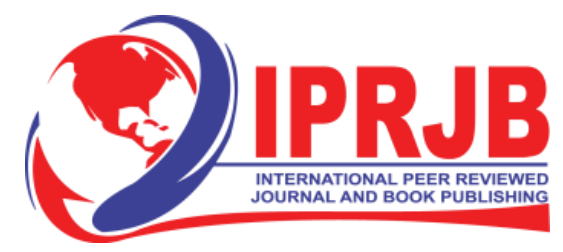

WWW.iprjb.org

Table 1: Leadership Attributes for Search and Selection Processes

\begin{tabular}{ll} 
Visionary & presents ideas for future organization improvement \\
\hline Empathetic & puts oneself in the shoes of others \\
\hline $\begin{array}{ll}\text { Adaptable/ } \\
\text { Flexible }\end{array}$ & pragmatic not ideological \\
\hline Resilient & performs in the face of adversity \\
\hline Innovator & creative and innovative \\
\hline People Skills & wins \& holds trust, builds support, motivates, persuades \\
\hline Integrity & honesty, candor, achieves moral authority \\
\hline Mental Acuity & mental vitality and stamina \\
\hline Responsible & willing and eager to accept responsibility \\
\hline Decisive & makes the tough decisions \\
\hline
\end{tabular}

\subsection{IDENTIFY A POSITION'S UNIQUE REQUIREMENTS TO EMPLOY AS EVALUATIVE STANDARDS}

When search committees assess candidates, they need to consider both their leadership attributes and the unique contextual requirements of the position to be filled. The position description is one source of insights into these unique requirements. However, position descriptions represent an organizational perspective and provide only one view of a role/position. Useful additional perspectives are 1) to explicitly consider the relationship between the position to be filled and diversity, social justice and inclusion concerns, and 2) to view positions as roles that will be performed within a Role Set and the expectations of those in counter roles.

The contemporary context for searches must consider the growing national dialog on social justice and inclusion. This dialog calls for a clear focus on the importance of being responsive to the need for diversity when staffing our educational institutions. Search Committees need to do more than just ensure that proper procedures have been followed. Each individual member needs to reflect on her/his personal core values and commitment to foster diversity. The search committee as a group needs to thoroughly discuss this topic and consider the organization's current demographics and the diversity status of the unit in question to arrive at a decision on the weight to place upon diversity (see Figure 3).

A classic study on Role Theory and Role Analysis was conducted at Harvard University in the 1950s. Gross, Mason and McEachern studied School District Superintendents in New England to better understand their high turnover rate. The main contribution of their 
Journal of Human Resource and Leadership

ISSN 2519-9099 (online)

Vol.5, Issue 1, No.4. pp 54 - 62, 2020

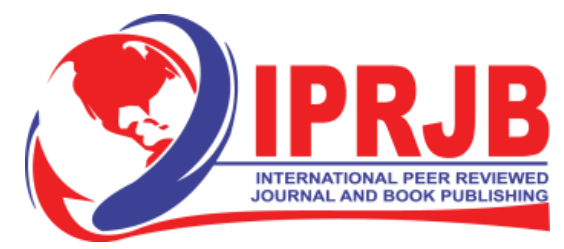

WWW.iprjb.org

study is the incredibly useful language they developed to perform Role Analyses. This language has been used in subsequent research studies. This article draws upon that language to illustrate one useful way to identify unique requirements of Roles (positions).

The Harvard researchers' language defines a Role as the set of expectations for the performance (behaviors) and attributes of incumbents of positions such as university presidents and officers. Examples of such behaviors are listening effectively, providing guidance to organizational constituents, and negotiating effectively with faculty and staff. Attributes are personal qualities such as those noted above under leadership attributes.

A Role Set is composed of a Focal Role (position) such as a university provost and Counter Roles such as board members, deans, faculty, staff, students, leaders of peer institutions, etc. In a university setting a dean's search might have the dean as the focal role and the provost, faculty, students, and alumni in counter roles. A Role Set is depicted graphically in Figure 2 below.

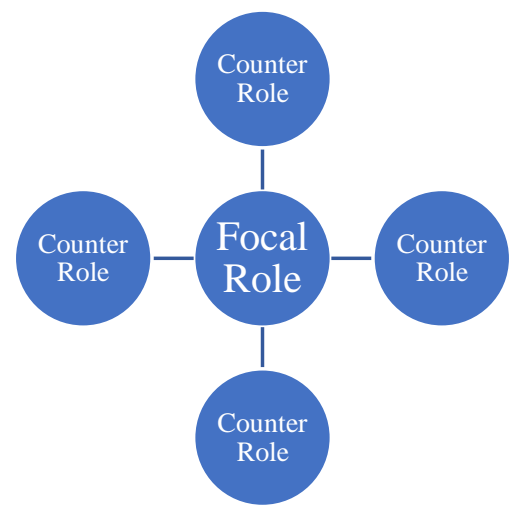

\section{Figure 2: A Generic Role Set}

The language of Role Analysis is relevant to search and selection processes. To illustrate this, we mention three of the concepts of this language and then comment on their utility for search committees.

Role Consensus exists when everyone's expectations of the (future) incumbent of the role are the same---a rare but desirable circumstance.

Role Conflict exists when expectations are not the same. Satisfying some expectations will mean not satisfying other expectations.

Role Ambiguity exists when there are uncertain expectations for the future incumbent role. This is often the case for new roles/positions and for those in which the performance of the prior incumbent was not successful.

A search committee needs to be cognizant of the nature and extent to which role consensus, conflict and ambiguity exist as they will need to factor this into their 
Journal of Human Resource and Leadership

ISSN 2519-9099 (online)

Vol.5, Issue 1, No.4. pp 54 - 62, 2020

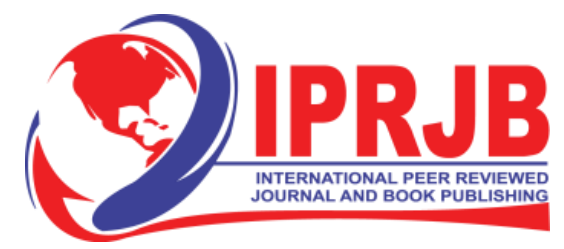

WWW.iprjb.org

assessments of the candidates and their ability to successfully perform in the role. Questions to consider include, but are not limited to:

- What are the differing expectations held for the role?

- What conflicting expectations exist?

- What are the reasons for the ambiguity?

- What attributes and skills are needed to cope with contextual realities?

- What are the candidate's own expectations regarding the role they are seeking?

Thinking about and answering these questions can help identify potential problems the selected individual will have to face and should help committees identify the unique contextual requirements of that role. In short, for candidate evaluation, an accurate reading of the context of the position is as important as a clear understanding of the position's description.

\subsection{SYSTEMATICALLY POOLING SUBJECTIVE JUDGMENTS}

Search Committees vary considerably in the extent to which they consider the structure and processes underlying their work. Ideally, they will make a number of judgments as they perform their work. For example, they may consider:

1. How to address diversity concerns?

2. What criteria to employ in screening the applicants' resumes? (Too often these criteria vary among committee members.)

3. What weights to place on these criteria? Which are more important?

4. How to score/rank the candidates using the weighted criteria?

5. Which candidates to invite to be interviewed? Why?

6. What questions to ask in the interviews? How are these chosen?

7. What bases to use to rank the interviewed candidates?

8. What rationale to provide for their recommended candidate?

Multi-Attribute Utility Analysis, a social science technique, is a way for search committees to structure their work by pooling committee members' judgments to help them assess candidates and make their selection recommendations. This section describes and illustrates how to use this decision analysis technique.

Our first example draws upon our discussion above on Leadership Attributes. Table 2 below shows ten leadership attributes along with attribute weightings, and the scores and weighted scores for an individual applicant. 
Journal of Human Resource and Leadership

ISSN 2519-9099 (online)

Vol.5, Issue 1, No.4. pp 54 - 62, 2020

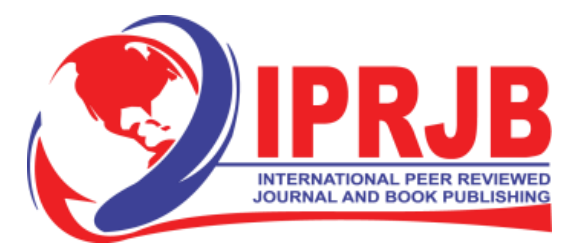

WWW.iprjb.org

Table 2: Leadership Attribute Analysis Format

\begin{tabular}{|l|c|c|c|}
\hline Applicant: & \multicolumn{3}{|c|}{} \\
\hline Attribute & $\begin{array}{c}\text { Weight } \\
\text { (out of 100) }\end{array}$ & $\begin{array}{c}\text { Score } \\
(1-10)\end{array}$ & $\begin{array}{c}\text { Weighted Score } \\
\text { (weight x score) }\end{array}$ \\
\hline Visionary & 10 & 6 & 60 \\
\hline Empathetic & 8 & 7 & 56 \\
\hline $\begin{array}{l}\text { Adaptability } \\
\text { Flexible }\end{array}$ & 8 & 8 & 64 \\
\hline Resilient & 12 & 8 & 96 \\
\hline Innovator & 8 & 9 & 72 \\
\hline People Skills & 14 & 10 & 140 \\
\hline Integrity & 14 & 9 & 64 \\
\hline Mental Acuity & 8 & 8 & 72 \\
\hline Responsible & 8 & 9 & 90 \\
\hline Decisive & 10 & 9 & 840 \\
\hline
\end{tabular}

Using the Table data above, some observations for a committee's consideration are: How many and which leadership attributes do you wish to use in your evaluative process for the particular position you are seeking to fill?

Do you want each committee member to assign weights to the attributes individually, or do you want to arrive at the weights through group discussion?

Scoring should be done individually and then the weighted scores calculated. These weighted scores can then be compiled for all committee members and then averaged to come up with the group's weighted score for each applicant.

Some additional thoughts for committees to consider are:

The weights in the illustration were assigned using an arbitrary total of 100; a committee could just as well decide to allocate a total of 1,000 points. The relative proportion of points assigned to an attribute is the important factor.

What is the best time to grapple with the desired leadership attributes, the position's unique requirements, and the weights to be placed upon them? If done before reading the applications, committee members will have a common frame of reference as they do their reading. If done after reading the applications, a second review will be necessary. It might be advisable to do a first scan of the applications to eliminate any candidates who clearly do not have the qualifications for the position, and then proceed to develop weighted attributes and scoring.

Subjective judgments are made at the points where attributes are selected, weights assigned, and scores given to applicants. These judgments are then pooled. It is important that these subjective judgments are made in a transparent way using a common frame of 
Journal of Human Resource and Leadership

ISSN 2519-9099 (online)

Vol.5, Issue 1, No.4. pp 54 - 62, 2020

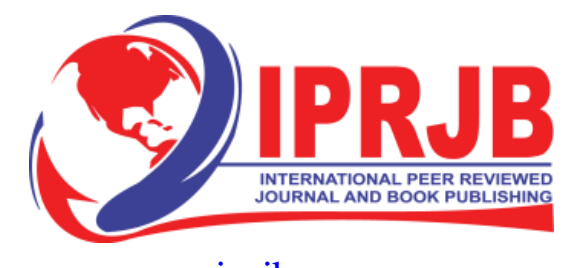

WwW.iprjb.org

reference which the committee has created. Working within a structured process like this avoids many of the pitfalls of the BOGGSATT process!

\subsection{POOLING SUBJECTIVE JUDGMENTS ABOUT UNIQUE CONTEXTUAL REQUIREMENTS}

Search Committees must do more than assess the leadership attributes of candidates; they also need to assess how well particular candidates 'fit' the organizational context and Role Set within which they will be expected to provide leadership. What expectations are held for the selected individual? What are the organization's most pressing problems and needs? What will the applicant be expected to achieve? Are these expectations in conflict? These expectations can best be discerned by seeking the input of individuals in Counter Roles of the Focal Position (See Figure 2). Hopefully, the search committee includes representatives from the various counter roles.

For illustrative purposes, let us assume we are the search committee for a Dean of a School of Business. We would expect to have the Provost brief the committee to provide a university level perspective on the strengths and weaknesses of the school, and the challenges the selected dean will be expected to address. Hopefully, faculty and student members of the committee will also provide input on the viewpoints of their constituencies. If alumni representatives are not on the committee, input can be sought from leaders of their organization. Peer input can be obtained from other universities' schools of business, and deans of other schools on the focal campus.

Table 3 below illustrates how contextual requirements can be addressed in the search and selection processes.

Table 3: Contextual Requirements Analysis Format

\begin{tabular}{|l|c|c|c|}
\hline Applicant: & \multicolumn{3}{|c|}{} \\
\hline $\begin{array}{l}\text { Contextual } \\
\text { Requirements }\end{array}$ & $\begin{array}{c}\text { Weight } \\
\text { (out of 100) }\end{array}$ & $\begin{array}{c}\text { Score } \\
(1-10)\end{array}$ & $\begin{array}{c}\text { Weighted Score } \\
\text { (weight x score) }\end{array}$ \\
\hline Diversity Concerns & 40 & 9 & 360 \\
\hline Budget Stringencies & 15 & 8 & 120 \\
\hline Faculty Unrest & 5 & 8 & 40 \\
\hline Donor Concerns & 15 & 10 & 150 \\
\hline Alumni Demands & 5 & 7 & 35 \\
\hline Student Satisfaction & 15 & 9 & 35 \\
\hline $\begin{array}{l}\text { Inter School } \\
\text { Relationships }\end{array}$ & 5 & 7 & 875 \\
\hline \multicolumn{1}{|c|}{} & 100 & & \\
\hline
\end{tabular}

Table 3 depicts a Business School which has gender and racial equity problems, is under fiscal stress, has a donor base that is underperforming, and a student body with some issues. This applicant is a minority woman whose references indicate she is well regarded 
Journal of Human Resource and Leadership

ISSN 2519-9099 (online)

Vol.5, Issue 1, No.4. pp 54 - 62, 2020

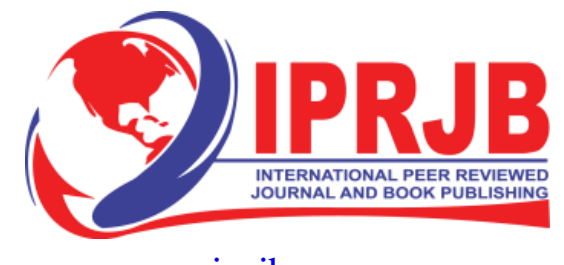

WWW.iprjb.org

in terms of her ability to work with donors and students, and deal with budgetary matters. The score sheet for the applicant may reflect the scoring of one search committee member or a summary of the pooled scores of all committee members. It is important to know that both the weighting and scoring processes have been accomplished in a transparent way and reflect the pooling of the subjective judgments of the committee members.

\subsection{SUMMARY AND CONCLUSION}

This paper has recommended the use of several theoretical/conceptual frameworks to structure Search Committee processes and improve their effectiveness in selecting the best qualified applicants for leadership roles. The paper also describes a decision analysis method which, if employed, will lower the degree of subjectivity in Search Committee decision making processes.

The argument we have advanced in this article is that search committees are more effective if they have followed an explicit structure and taken a systematic approach to pool the subjective judgments of their members in order to select and weight the criteria to use to score applicants. We provided descriptions of how multi-attribute utility analysis can be employed to assess the leadership attributes of candidates, and how well they fit the contextual requirements of the role their search is addressing.

\section{REFERENCES}

Bennis, Warren. (2009). The Essential Bennis: Essays on Leadership. San Francisco: Jossey-Bass.

Edwards, W. and Winterfeldt, Detlof Von. (2003). Decision Analysis and Behavioral Research. New York: Cambridge University Press.

Gardner, John. (1990). On Leadership. New York: The Free Press.

Gates, Robert M. (2016). A Passion for Leadership. New York: Alfred A. Knopf.

Gross, Neal; Mason, Ward S.; and McEachern, Alexander W. (1958). Explorations in Role Analysis. New York: John Wiley and Sons.

Keeney, R.L. and Raiffa, H. (1993). Decisions with Multiple Objectives: Preferences and Value Trade-offs. New York: Cambridge University Press.

Stavridis, James. (2019). Sailing True North. New York: Penguin Random House.

Wikipedia. (2019). Multi Attribute Utility Analysis. 